\section{Photosynthetic Acclimation of Sweet Pepper Plants to Screenhouse Conditions}

\author{
Evagelini Kitta \\ Centre for Research \& Technology Hellas, Dimitriados 95 \& P. Mela, 38333, \\ Volos, Greece
}

Nikolaos Katsoulas ${ }^{1}$ and Anna Kandila
University of Thessaly, Department of Agriculture Crop Production and
Rural Environment, Fytokou Str, 38446, Volos, Greece

Maria M. González-Real and Alain Baille

Universidad Politécnica de Cartagena, Escuela Técnica Superior de Ingenieros Agrónomos, Área de Ingeniería Agroforestal, Paseo Alfonso XIII, 48, 30203, Cartagena, Spain

Additional index words. light-use efficiency, net $\mathrm{CO}_{2}$ assimilation, shading, transpiration, water-use efficiency

\begin{abstract}
Leaf gas exchange and photosynthetic light acclimation of sweet pepper leaves were investigated in a Mediterranean area (central Greece) in the open field and in three screenhouse nets differing in color, shading intensity (SI), and porosity from May to Oct. 2011. The screenhouse nets were two insect-proof white nets (W13 and W34, SI $=13 \%$ and $34 \%$, respectively) and a green shading net $(\mathrm{G36}, \mathrm{SI}=36 \%)$. Leaf net $\mathrm{CO}_{2}$ assimilation $\left(A_{n}\right)$, transpiration rate $(E)$, and stomatal conductance $\left(g_{\mathrm{S}}\right)$ were measured by means of a portable gas exchange device on leaves located in three canopy layers. The differences in light regime within the canopy induced by the three shading nets had only a slight effect on $A_{n}$, thereby resulting in substantially higher light-use efficiency under shading than in the open field. The observed tendency toward higher $g_{S}$ in shaded plants was counterweighted by a lower intercellular-to-ambient $\mathrm{CO}_{2}$ concentration gradient, leading to similar $A_{\mathrm{n}}$ in leaves of shaded and non-shaded plants. Ontogenic effects (leaf aging) appeared to be the main factor determining the decreasing seasonal trend of leaf photosynthetic attributes. Overall, shaded sweet pepper plants display a physiological light acclimation allowing them to maintain the photosynthetic activity to a level similar to that observed in non-shaded plants across a wide range of growth light regimes, irrespective of the type of net and its shading intensity.
\end{abstract}

Reductions in photosynthetic activity and/or in assimilate partitioning to the fruits, negatively affecting crop yield, are frequently observed for open-field crops grown in Mediterranean regions where plants are subjected to high radiation load and low air relative humidity during a great part of the crop cycle (Aloni et al., 1990; Dinar and Rudich, 1985; Erickson and Markhart, 2001). An alternative to alleviate the effects of radiation load is the use of reflection or shading (whitening, internal or external screens). Shading conditions, creating a light regime compatible with the requirements of leaf physiological functions (Barber and Anderson, 1992), have been proven to induce a positive impact on leaf gas exchange (Gonzalez-Real and Baille, 2006; Jaimez and Rada, 2011) and

Received for publication 17 July 2013. Accepted for publication 10 Dec. 2013.

We thank Agroplast-Hatzikosti Bros. for providing the anti-thrip nets tested in this study and Plantas S.A. for supplying the pepper plant seedlings.

${ }^{1}$ To whom reprint requests should be addressed; e-mail nkatsoul@uth.gr. on plant growth and crop yield in several crops (Baille et al., 2001; Gent, 2007; Lorenzo et al., 2003) including sweet pepper (Jaimez and Rada, 2011; Rylski and Spigelman, 1986a, 1986b). The latter, like other species, is sensitive to high temperature (Erickson and Markhart, 2001, 2002; Rylski and Spigelman, 1982) but appear to maintain their leaf net $\mathrm{CO}_{2}$ assimilation rates at temperatures as high as $33{ }^{\circ} \mathrm{C}$ in detriment of developing fruits (Erickson and Markhart, 2001).

Screenhouses seem to be a valuable alternative to reduce radiation load, because they can simultaneously act as cover and shading devices. These low-cost structures have been progressively adopted by growers in the last decade (Castellano et al., 2008) as shown by the increasing area of field-grown crops that shifted to screenhouse (Cohen et al., 1997, 2005; Kittas et al., 2012; Tanny and Cohen, 2003). In particular, the use of insect-proof nets raised much interest among growers, because they limit the use of pesticides and associated costs through implementation of Integrated Pest and Disease Management strategies favoring a production of quality (Raviv and Antignus, 2004; Reuveni et al., 1989).
Screenhouses substantially modify the radiation regime with respect to the outside conditions, both quantitatively, through reduction of photosynthetic photon flux density $(P P F D)$ reaching the crop, and qualitatively, through changes in the ratio of diffuse-todirect radiation (Healey et al., 1998) and the spectral distribution of solar radiation (Ehret et al., 1989; Kittas and Baille, 1999). With regard to open-field crops, the radiative microclimate under a screenhouse can lead to modifications in leaf physiological attributes and carbon allocation patterns, which in turn affects crop yield and quality (Rylski and Spigelman, 1986a, 1986b). The wide range of plant response to artificial or natural shading reported in the literature (Cockhull et al., 1992; Jaimez and Rada, 2011; Li et al., 2000; Raveh et al., 2003; Stanhill and Cohen, 2001) can be related to 1) differences in screen physical properties (e.g., porosity) and shading duration and intensity (Gent, 2007); 2) stage of plant development (Cohen et al., 2005); 3) plant density (Papadopoulos and Pararajasingham, 1997); and 4) response of leaf structural and physiological attributes to changes in local light regime (e.g., Egea et al., 2012).

A large body of studies, focusing on light acclimation of leaf physiological function, stressed the close relationship between the distribution of photosynthetic traits and the local light regime in species grown in the open field (Field and Mooney, 1986; Niinemets et al., 2004) and under greenhouses (Acock et al., 1978; González-Real et al., 2007; Gonzalez-Real and Baille, 2000) including pepper crops (Dueck et al., 2006; GonzálezReal et al., 2009). Changes in the light environment may induce a wide range of structural and physiological changes such that the photosynthetic capacity of uppermost leaves can reach values more than 2 -fold higher than that of the bottom leaves (Niinemets, 2007).

In sweet pepper, the impact of light may interfere with the internal control induced by either the presence or removal of fruits (Gucci and Flore, 1989; Hall, 1977), which are known to exhibit strong temporal changes in their demand for assimilates at different stages of growth (González-Real et al., 2009). Therefore, knowledge about plasticity in leaf physiological function and its interaction with leaf ontogeny in response to light distribution within the crop is determinant not only for assessing crop carbon uptake, but also for characterizing the impact of greenhouse agronomic practices (e.g., pruning and defoliation strategies) on crop yield (Adams et al., 2002; Heuvelink et al., 2005).

To our knowledge, an important issue not yet fully investigated in screenhouses concerns plant acclimation to the light regime imposed by the screen. The present work deals with the effects of three screen materials having different color, porosity, and SI on leaf physiological attributes of the sweet pepper, which is a horticultural species of great economical importance in Mediterranean countries. The specific objectives of our study were 1) to characterize gas exchange of 
sweet pepper plants under open-field and screenhouse growing conditions; and 2) to evaluate the degree of acclimation of photosynthetic leaf attributes to different light regimes during a summer-fall growth cycle in a Mediterranean region (central Greece). Additionally, leaf water-use efficiency and light-use efficiency were analyzed.

\section{Materials and Methods}

Screenhouse and open-field facilities. The experiments were performed in an open field [control treatment (OF)] and in three experimental flat roof screenhouses with the longer dimension oriented north to south, located at the University of Thessaly near Volos (Velestino: lat. N $39^{\circ} 22^{\prime}$, long. E $22^{\circ} 44^{\prime}$, altitude $85 \mathrm{~m}$ ), in central Greece, from May to Oct. 2011. The three screenhouses were $20 \mathrm{~m}$ long, $10 \mathrm{~m}$ wide, and $3.2 \mathrm{~m}$ high. Two of them were covered by an antithrip net 50 mesh (round monofilament threads of $0.24 \mathrm{~mm}$ diameter, 50 threads per inch) with SI of 1) 13\% (W13) for the perl net (AntiVirus ${ }^{\mathrm{TM}}$; Meteor Agricultural Nets Ltd., Israel); and 2) 34\% (W34) for the white net (BioNet ${ }^{\mathrm{TM}}$; Meteor Agricultural Nets Ltd.). The third one (3) was covered by a green shading net ( $\mathrm{SI}=36 \%$, G36) (Thrace Plastics Co S.A., Xanthi, Greece). The values of SI correspond to measurements performed in laboratory within the wavelength range 250 to $800 \mathrm{~nm}$, by means of a spectroradiometer (Model LI-1800; LICOR, Lincoln, NE) equipped with a $10-\mathrm{W}$ glass halogen lamp and an external integrating sphere (Model LI-1800-12S; LI-COR). The soil under the screenhouses and in the open field was completely covered by black polypropylene mulch.

Plant material. Sweet pepper plants (Capsicum annuum L., cv. Dolmi) were transplanted in the three screenhouses and in open field on 31 May 2011 [days after transplant $(\mathrm{DAT})=0]$ and grown until 30 Oct. 2011 $(\mathrm{DAT}=153)$. Plants were laid out $0.5 \mathrm{~m}$ apart between rows in five double rows with a distance between double rows of $1.2 \mathrm{~m}$ and a distance between plants of the same row of $0.5 \mathrm{~m}$. Plants were supported vertically by cords hanging from cables attached longitudinally to the frame of the screenhouses. In the four treatments (W13, W34, G36, and OF), the plants were treated following the Spanish method in which the plants are allowed to grow without pruning (Jovicich et al., 2004). Irrigation water was supplied through drip-laterals with one dripline per row and one dripper per plant. The dripper flow rate was $4 \mathrm{~L} \cdot \mathrm{h}^{-1}$. In all treatments, irrigation scheduling was based on the concept of crop coefficient, $\mathrm{K}_{\mathrm{c}}$, as described in Katsoulas et al. (2006). The amount of water supplied to the crop was calculated as the product of $\mathrm{K}_{\mathrm{c}}$ and a fixed integral of solar radiation $\left(21.5 \mathrm{MJ} \cdot \mathrm{m}^{-2}\right)$. The value of $\mathrm{K}_{\mathrm{c}}$ was fixed to a level that ensured that the crops were fully watered during the months with the highest water demand $\left(\mathrm{K}_{\mathrm{c}}=0.54\right.$, corresponding to a water dose of $4.61 \mathrm{~mm})$. It can be considered that all crops were maintained fully watered and did not suffer from soil water deficit throughout the crop cycle.

Climatic data. The following climatic data were continuously monitored during the whole growth cycle in the center of each screenhouse and in the open field: 1) air temperature and vapor pressure deficit (VPD) by means of temperature and humidity sensors (WiSensys ${ }^{\circledR}$ Wireless Sensor WS-DLTc; Wireless Value BV, The Netherlands) located $1.5 \mathrm{~m}$ aboveground; and 2) PPFD (in $\mu \mathrm{mol} \cdot \mathrm{m}^{-2} \cdot \mathrm{s}^{-1}$ ) by means of quantum sensors (Model LI-190SA; LI-COR, Lincoln, NE). Data were recorded on a data logger (Model DL3000, Delta-T Devices, Cambridge, U.K.). Measurements took place every $30 \mathrm{~s}$ and their average values were recorded every $10 \mathrm{~min}$.

Gas exchange measurements. Leaf net $\mathrm{CO}_{2}$ assimilation, $E, g_{\mathrm{S}}$, external $\left(C_{\mathrm{a}}\right)$ and intercellular air $\mathrm{CO}_{2}$ concentration $\left(\mathrm{C}_{\mathrm{i}}\right)$, and leaf surface temperature were determined by means of a portable photosynthesis system (LCpro+; ADC BioScientific Ltd., U.K.) equipped with a chamber using a constant leaf area $\left(5.2 \mathrm{~cm}^{2}\right)$. Measurements were performed about every $20 \mathrm{~d}$ on 10 healthy leaves per treatment randomly selected in each leaf layer. All measurements were made under ambient conditions on clear sunny days around midday. During each measurement run, values of air temperature and air actual vapor pressure in the chamber were kept near those prevailing in the ambient. From planting to end of July (Period 1), measurements were performed in Layer 1. From August to mid-September (Period 2, $61<$ DAT < 110), measurements were carried out in two layers (Layer 1: bottom layer with adult leaves and Layer 2: uppermost layer with young leaves). From mid-September until the end of the growth cycle $(110<$ DAT $<153$, Period 3$)$, three layers were considered (Layer 1: old leaves of the bottom layer, Layer 2: adult leaves of the middle layer, and Layer 3: young leaves of the uppermost layer). The final plant height reached by the pepper plants was $\approx 1.2 \mathrm{~m}$ and each leaf layer was assumed to account for one-third of the final plant height. The amount of $P P F D$ prevailing in the middle of each leaf layer was measured by a silicon cell sensor fixed to the support of the chamber. All measurements were carried out around midday to ensure that the amount of $P P F D$ reaching the leaves was near the photosynthetic light saturation rate from May to October. The saturation rate was found to be $\approx 1200,1000$, and $800 \mu \mathrm{mol} \cdot \mathrm{m}^{-2} \cdot \mathrm{s}^{-1}$ for Layers 1, 2, and 3, respectively (Liu and González-Real, unpublished data) but might depend on cultivar and growth conditions (Jaimez and Rada, 2011).

Shade acclimation parameters. The response of a physiological trait $X$ to shading was characterized by a shade adjustment coefficient $(\sigma)$ as proposed by various authors (e.g., Egea et al., 2012; Laisk et al., 2005):

$$
\sigma(X)=1-X_{\mathrm{S}} / X_{\mathrm{OF}}
$$

where $X_{\mathrm{S}}$ and $X_{\mathrm{OF}}$ are the values of $X$ in the screenhouse and in the open field, respectively. According to this equation:

$$
\begin{aligned}
& \text { if } \mathrm{X}_{\mathrm{S}}<\mathrm{X}_{\mathrm{OF}} \text { then } \sigma>0 \\
& \text { if } \mathrm{X}_{\mathrm{S}}>\mathrm{X}_{\mathrm{OF}} \text { then } \sigma<0
\end{aligned}
$$

It should be noted that $\sigma$ accounts for the combined effects of shading material and progressive shading induced by the uppermost leaf layers.

Statistical analysis. A statistical package SPSS (SPSS-14.0 for Windows standard version, 2005; SPSS BI Greece S.A., Greece) was used for statistical analysis of the data. Data were analyzed using analysis of variance $(P \leq 0.05)$ and Duncan's multiple range post hoc tests.

\section{Results}

Mean daytime values (averaged over 0800 to $2000 \mathrm{HR}$ ) of air temperature and air VPD observed in the screenhouses (W13, W34, and G36) and in the OF from August to September are given in Table 1.

$P P F D$ regime within the canopy. The seasonal evolution of $P P F D$ measured in Layer 1 showed a clear downward trend for the four treatments (Fig. 1). This behavior was attributable to both the seasonal decrease of the outside solar radiation from June to October and the progressive shading of Layer 1 by the leaves of Layers 2 and 3 . The amount of PPFD reaching the leaf layers was substantially lower for the screenhouse-grown crops than for the OF crop. On average over the observation period, the ratio of screenhouse to OF PPFD in Layer 1 was found to be $0.62( \pm 0.04), 0.49( \pm 0.04)$, and $0.54( \pm 0.02)$ for W13, W34, and G36, respectively. A similar decreasing PPFD trend was observed for Layer 2 (data not shown).

Net $\mathrm{CO}_{2}$ assimilation. $A_{\mathrm{n}}$ showed a similar trend in Layers 1,2, and 3 in the four treatments throughout the growth cycle (May to October)

\begin{tabular}{|c|c|c|c|c|c|c|c|c|}
\hline \multirow[b]{2}{*}{ Month } & \multicolumn{4}{|c|}{$\mathrm{T}_{\mathrm{a}}\left({ }^{\circ} \mathrm{C}\right)$} & \multicolumn{4}{|c|}{$\mathrm{VPD}(\mathrm{kPa})$} \\
\hline & $\mathrm{OF}$ & W13 & W34 & G36 & OF & W13 & W34 & G36 \\
\hline September & $26.3 \pm 3.5$ & $26.7 \pm 4.4$ & $26.3 \pm 4.1$ & $25.9 \pm 3.9$ & $1.8 \pm 0.7$ & $1.9 \pm 0.7$ & $1.8 \pm 0.7$ & $1.8 \pm 0.6$ \\
\hline
\end{tabular}

Table 1. Mean values ( $( \pm \mathrm{SD})$ of air temperature $\left(\mathrm{T}_{\mathrm{a}}\right)$ and vapor pressure deficit (VPD) observed in the three screenhouses (W13, W34, and G36) and in the open field (OF) between 0800 and 2000 HR local time during Aug. and Sept. 2011. 


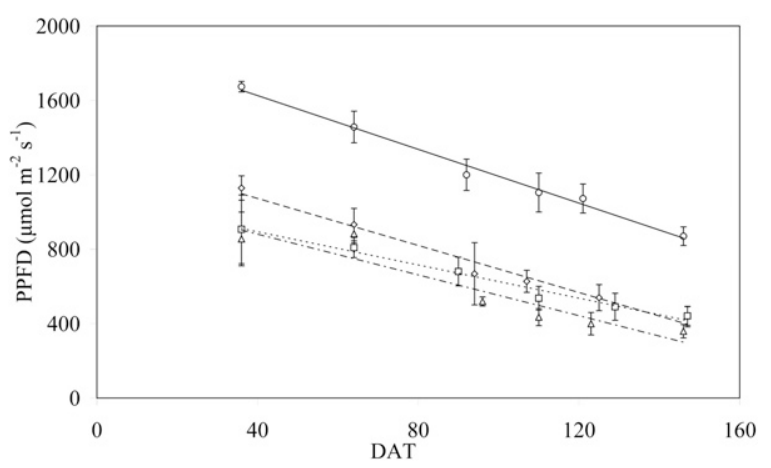

Fig. 1. Photosynthetic photon flux density $(P P F D)$ measured in Layer 1 at different days after transplant (DAT), in the open field $(\bigcirc$, OF) and in the three screenhouses $(\diamond: \mathrm{W} 13 ; \triangle$ : W34 and $\square$ : G36). Measurements performed on sunny days, near noon. Lines are best fit regressions to the data.

(Fig. 2A) with no significant differences among the four treatments. A sharp decline of $A_{\mathrm{n}}$ was observed in Layer 1 at DAT $\approx 60$ with $A_{\mathrm{n}}$ reaching quite conservative values from DAT $\approx 90$ onward. This trend is quite similar to that observed in Layer 2, for which a sharp decrease of $A_{\mathrm{n}}$ was observed at DAT $\approx 120$, that is, with a delay of $\approx 60 \mathrm{~d}$ with respect to Layer 1.

To summarize, the large differences in the within-canopy light regime among the screenhouses and the OF (Fig. 1) had only a moderate effect on the magnitude of $A_{\mathrm{n}}$ (Fig. 2A) and no clear effect on its seasonal pattern.

The shade acclimation coefficient $\left(\sigma_{A}\right)$ for net $\mathrm{CO}_{2}$ assimilation (Fig. $3 \mathrm{~A}$ ) was slightly positive $\left(\sigma_{\mathrm{A}} \approx 0.05\right.$ to 0.10 ) at the early and adult plant stages (DAT $<120)$ and moderately positive $\left(\sigma_{\mathrm{A}} \approx 0.20\right)$ at the senescent stage (DAT > 120), indicating that the screenhouse-shaded plants had similar leaflevel photosynthetic performance than the OF plants. We did not observe statistically significant differences in $\sigma_{\mathrm{A}}$ among the three screenhouses, except near the end of the crop cycle $($ DAT $=125)$ when G36 exhibited higher net $\mathrm{CO}_{2}$ assimilation rates than $\mathrm{W} 13$ (Fig. 3A).

Transpiration rate. The overall trend of $E$ throughout the crop cycle was characterized by a continuous decrease in all layers, although in a more progressive way than that observed for $A_{\mathrm{n}}$ (Fig. 2B). No significant differences were observed on the $E$ values measured under the four treatments, except for DAT 40 when the $E$ values measured for G36 were significantly lower than in the rest of treatments. The trend of $\sigma_{\mathrm{E}}$ was not consistent along the crop cycle as observed for the rest of shade acclimation coefficients for which $\sigma$ tended to be slightly positive $\left(0>\sigma_{\mathrm{A}}<+0.1\right.$, DAT $\leq 107)$, consistently positive $\left(\sigma_{\mathrm{A}}\right.$, DAT $>107$, and $\left.\sigma_{\text {WUE }}\right)$, or consistently negative $\left(\sigma_{\mathrm{g}}, \sigma_{\mathrm{LUE}}\right.$, and $\sigma_{\mathrm{C}}$ for a great part of the experimental period) attributable to, respectively, similar, lower, and higher values of the corresponding physiological trait under a screenhouse than in the OF.

As previously observed for $\sigma_{\mathrm{A}}$, significant differences in $\sigma_{\mathrm{E}}$ among the screenhouses were only observed within DAT 125 to 147 .
As a result of the large SD of the mean values, some large differences observed at the end of the crop cycle (e.g., DAT 107) were not statistically significant. $E$ rates tended to be higher under the screenhouse as compared with $\mathrm{OF}$ at the middle and at the end of the crop cycle, especially under W34 (DAT within 107 to 147$)$ and W13 (DAT $=125)$. Values of $\sigma_{\mathrm{E}}$ did not show statistically significant differences among the three screenhouses, except at DAT $=125$ when $\mathrm{W} 13$ and 34 both showed significantly higher $\sigma_{\mathrm{E}}$ values than G36 (Fig. 3B). As for $A_{n}, E$ decreased as leaves aged and the differences in the within-canopy light regime among screenhouses and the OF only had no clear effect on either the magnitude of $E$ or its seasonal pattern.

Stomatal conductance. The evolution of $g_{\mathrm{S}}$ throughout the crop cycle was less regular and more complex than that exhibited by $A_{\mathrm{n}}$ and $E$. The highest values of $g_{\mathrm{S}}$ were observed for the first period $(0<$ DAT $<60)$ with rather similar values in all treatments $\left(\approx 0.25 \mathrm{~mol} \cdot \mathrm{m}^{-2} \cdot \mathrm{s}^{-1}\right)$. As for $A_{\mathrm{n}}$, a sharp decrease occurred after DAT 60 , the minimum values $\left(\approx 0.10 \mathrm{~mol} \cdot \mathrm{m}^{-2} \cdot \mathrm{s}^{-1}\right)$ being reached near DAT 100. An increase in $g_{S}$ was observed in all treatments from DAT $>100$ until the end of the growth cycle. The values of $g_{\mathrm{S}}$ of screenhouse plants were higher than the corresponding values of $g_{\mathrm{S}}$ in OF throughout the crop cycle (data not shown) with statistically significant differences observed only between the OF and the W34 crops with only slight differences during the first period $\left(\sigma_{\mathrm{g}} \approx-0.10\right)$ but large differences at the senescent stage, when $\sigma_{\mathrm{g}}$ could reach values close to -1.70 (Fig. 3C). As observed for $\sigma_{\mathrm{A}}$ and $\sigma_{\mathrm{E}}$, differences in $\sigma_{\mathrm{g}}$ among the screenhouses were also observed toward the end of the crop cycle (W13 had significantly higher $\sigma_{\mathrm{g}}$ values than $\mathrm{G} 36$ at DAT $=125$; the reverse being true at DAT = 147; Fig. 3C).

Intracellular-to-ambient $\mathrm{CO}_{2}$ ratio. The ratio of intercellular-to-ambient $\mathrm{CO}_{2}$ concentration $\left(C_{\mathrm{i}} / C_{\mathrm{a}}\right)$ showed a continuous increasing trend with leaf aging, starting from values of $\approx 0.45$ to $0.50(\mathrm{DAT}<60)$ in all treatments and increasing until $\approx 0.75$ and 0.90 in the $\mathrm{OF}$ and in the most shaded crops (W34 and G36), respectively. The values of $C_{\mathrm{i}} / C_{\mathrm{a}}$ of screen- house plants were significantly higher than the corresponding values in OF (data not shown), the relative differences being on average of $\approx 20 \%$. The screenhouses did not exhibit statistically significant differences in $\sigma_{\mathrm{C}}$ during most of the crop cycle (Fig. 3D), except around the middle of the crop cycle when values of $\sigma_{C}$ were all lower than 0.1 .

Light-use efficiency. The light-use efficiency (LUE, in mole $\mathrm{CO}_{2}$ fixed per mole of incident $P P F D$ ) decreased with leaf aging (Fig. 2C), showing a pattern close to that observed for $A_{\mathrm{n}}$ (Fig. 2A). LUE in the screenhouse treatments were significantly higher than in the OF throughout the whole crop cycle, as illustrated by the strongly negative values of the shade acclimation coefficient, $\sigma_{\text {LUE }}$ (Fig. 4A). Plants growing under the W34 screenhouse experienced the highest increase in LUE with respect to the OF plants with $\sigma_{\text {LUE }}$ reaching values lower than -1 . However, the latter only exhibited statistically significant higher values than $\mathrm{W} 13$ and G36 at DAT $=94$ and than G38 toward the end of crop cycle (DAT 125) (Fig. 4A).

Intrinsic water-use efficiency. The intrinsic leaf water-use efficiency $\left(\mathrm{WUE}_{\mathrm{i}}=A_{\mathrm{n}} / g_{\mathrm{S}}\right.$ in $\mu \mathrm{mol} \cdot \mathrm{mol}^{-1}$ ) was maximum at the beginning of the crop cycle in all treatments, ranging from 70 to $90 \mu \mathrm{mol} \cdot \mathrm{mol}^{-1}$. WUE decreased more or less steadily toward a minimum value at the end of the cropping cycle reaching values within 20 to $50 \mu \mathrm{mol} \cdot \mathrm{mol}^{-1}$ (Fig. 2D). OF plants exhibited the highest values of $\mathrm{WUE}_{\mathrm{i}}\left(\mathrm{WUE}_{\mathrm{i}}=90\right.$ and 50 $\mu \mathrm{mol} \cdot \mathrm{mol}^{-1}$, at the beginning and at the end of the crop cycle, respectively). Statistical analysis revealed that OF plants had significantly higher $\mathrm{WUE}_{\mathrm{i}}$ values than $\mathrm{W} 13$ and W34 plants and similar $\mathrm{WUE}_{\mathrm{i}}$ values to G36 plants. It was observed a generalized increasing trend of the shade acclimation coefficient for $\mathrm{WUE}_{\mathrm{i}}, \sigma_{\mathrm{WUE}}$ (Fig. 4B), throughout the crop cycle in the screenhouse plants. We did not observe statistically significant differences in $\sigma_{\text {WUE }}$ among the shading treatments during the crop cycle (Fig. 4B).

\section{Discussion}

Photosynthesis acclimation. Despite the substantial difference observed on the incident $P P F D$ between screenhouses and the OF (Fig. 1), $A_{\mathrm{n}}$ of the shaded crops was similar to (DAT $<100$ ) or slightly lower $(\mathrm{DAT}>100)$ than that of OF crop (Figs. 2A and 3A). This behavior was also observed in Capsicum chinense (Jaimez and Rada, 2011) under conditions of high radiation load prevailing in $\mathrm{OF}$, but only when the percentage of shade was low or moderate (less than 50\%). Erickson and Markhart (2001) observed a positive impact on $A_{n}$ of high temperature in plants grown at $33{ }^{\circ} \mathrm{C}$ compared with those grown at $25{ }^{\circ} \mathrm{C}$. However, this behavior was accompanied by a sensible reduction in fruit set, independently of VPD conditions, as a result of pepper failure to set fruit at $33{ }^{\circ} \mathrm{C}$. Aloni et al. (1996) did not observe higher $A_{\mathrm{n}}$ in pepper plants grown at high temperature but changes in the 

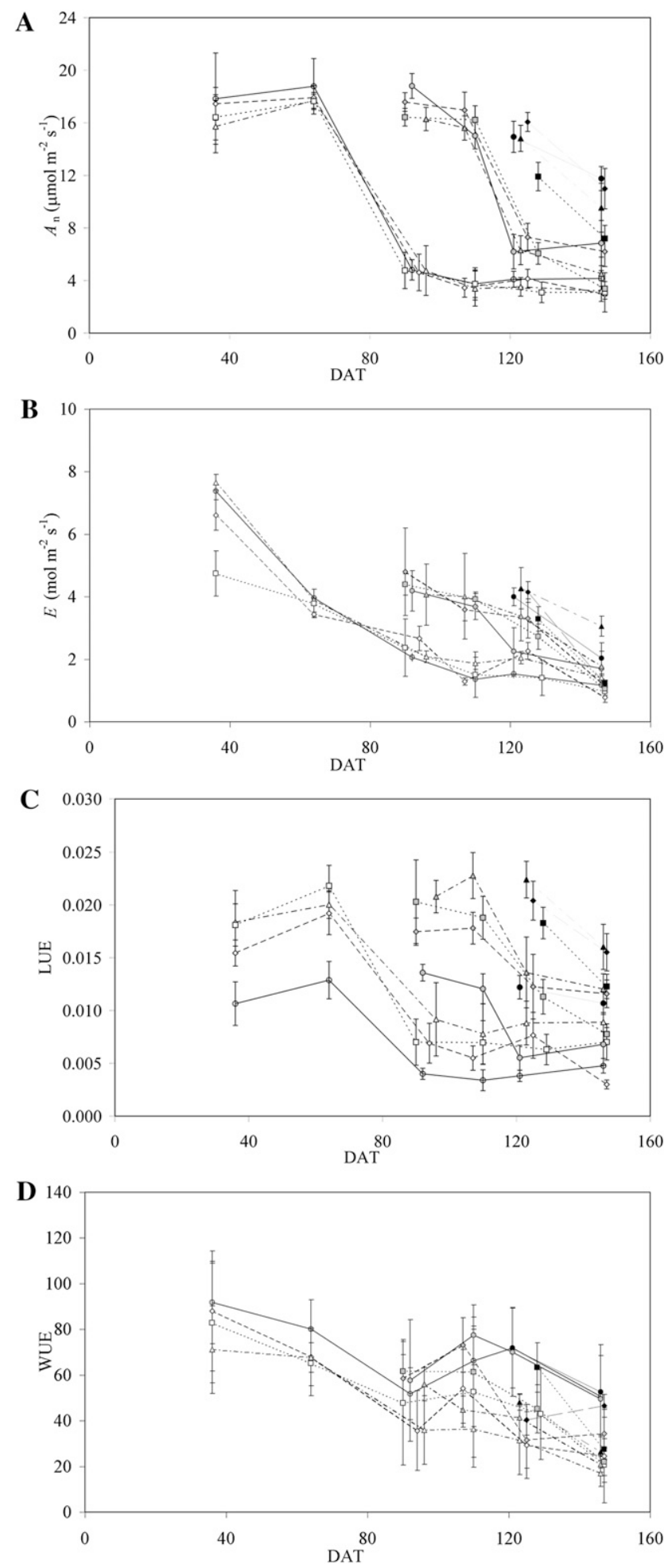

Fig. 2. Seasonal evolution of leaf physiological attributes measured in the three different leaf layers during the experimental period near noon in the open field $(O$, OF $)$ and in the three screenhouses $(\diamond: \mathrm{W} 13 ; \triangle$ : W34 and $\square$ : G36). (A) Net $\mathrm{CO}_{2}$ assimilation $\left(\mathbf{A}_{\mathrm{n}}\right)$, (B) leaf transpiration rate $(E)$, (C) light-use efficiency (LUE), and (D) intrinsic water use efficiency (WUE). Open, gray, and black symbols for Layers 1, 2, and 3, respectively. Vertical bars: \pm SD.

partitioning of assimilates toward the young leaves in detriment to flowers and flower buds. The results of Erickson and Markhart (2001) support the hypothesis of Aloni et al. (1996) that pepper plants are able to maintain their rates of net $\mathrm{CO}_{2}$ assimilation at high temperature in detriment of developing re- productive structures. The fact that in our experimental conditions OF plants were able to maintain relatively high $A_{n}$ suggests that heat- and radiation-induced stress had not occurred in the OF crop and may help explain the relatively low differences in net $\mathrm{CO}_{2}$ assimilation rate among $\mathrm{OF}$ and screenhouse plants.
Overall, the seasonal trend of $A_{\mathrm{n}}$ was similar in all treatments with a plateau followed by a sharp decline at DAT 90 (first flush in fruit set) for leaves of Layer 1 and at DAT 140 (second flush in fruit set) for leaves of Layer 2 (Fig. 2A). The sharp decline in $A_{n}$ was concomitant with leaf aging, but probably also with a decrease in photosynthetic nitrogen $(\mathrm{N})$ allocation to the leaves, which are competing with high $\mathrm{N}$-demanding organs (fruits) for N resources. Precisely, DAT 90 corresponds to the onset of the first flush of fruits and DAT 140 to the onset of the second flush (data not shown). These results suggested that cyclic patterns of yield (fruit flushes, typical of peppers crops) affect the priority with which $\mathrm{N}$ is attributed to leaves. Therefore, ontogenic processes (e.g., leaf aging) along with $\mathrm{N}$ allocation to leaves (Gonzalez-Real and Baille, 2000) seemed to be the predominant factor in driving the seasonal pattern of leaf net $\mathrm{CO}_{2}$ assimilation.

Transpiration and $g_{S}$ acclimation. Higher values of $g_{\mathrm{S}}$ along the crop cycle in the shade treatments (although not always statistically significant) with respect to the OF (Fig. 3C) did not result in corresponding higher $E$ rates except in some treatments around the middle (in W13 and W34, $P<0.05$ at DAT 125) and at the end (in W34, $P<0.05$ ) of the crop cycle. The generalized decreasing trend of $E$ with leaf aging (Fig. 2B) could be related to that of $g_{\mathrm{S}}$, although the two attributes showed different short-term adjustments (Fig. 3B-C).

$C_{i} / C_{a}$ ratio. Both leaf aging and shading affected the internal $\mathrm{CO}_{2}$ concentration. The values of the ratio $C_{i} / C_{a}$ were higher (i.e., lower values of the intercellular-to-ambient $\mathrm{CO}_{2}$ gradient because $C_{a}$ was nearly constant during the period of measurements) in shaded plants compared with those of the OF (Fig. $3 \mathrm{D})$. This behavior suggests that $g_{\mathrm{S}}$ is not the main determinant of the corresponding decrease experienced by $A_{\mathrm{n}}$ with both leaf aging and shading by restricting the $\mathrm{CO}_{2}$ availability in the mesophyll (Lawlor, 2002). It can be drawn that the tendency toward higher $g_{\mathrm{S}}$ under shade was counterweighted by a lower $\mathrm{CO}_{2}$ gradient, therefore explaining the similar magnitude of $A_{\mathrm{n}}$ in OF and screenhouse plants.

Light-use efficiency. LUE of pepper leaves was substantially higher under a screenhouse than in the OF (Fig. 4A). For young and photosynthetic active leaves (DAT $<60$ ) of the shade treatments, the relative increase in LUE (from $\approx 50 \%$ to $60 \%$ ) with respect to the OF treatment (Fig. 2C) was close to or slightly higher than the corresponding decrease in incident PPFD (Fig. 1).

Noteworthy, the relative increase in LUE of shaded adult and old leaves (DAT $>100$ ) with respect to OF plants was substantially higher than the corresponding relative decrease in incident $P P F D$ with more than $100 \%$ increase in LUE under the $34 \%$ shade treatment (W34, Fig. 4A). A possible explanation might be that the amount of light under a screenhouse after DAT 100 did not reach the saturation level $\left(\approx 1000\right.$ to $1200 \mu \mathrm{mol} \cdot \mathrm{m}^{-2} \cdot \mathrm{s}^{-1}$ for the uppermost leaves, depending on cultivars 

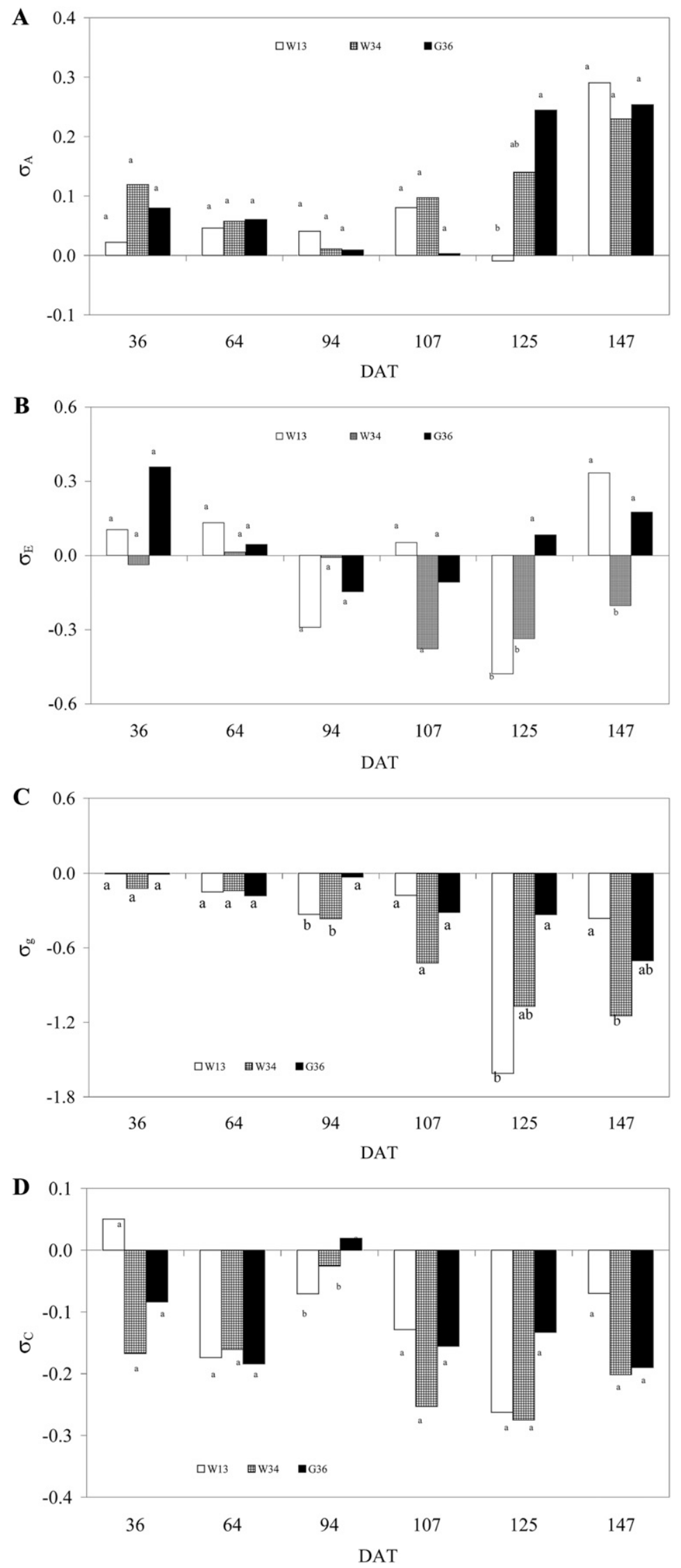

Fig. 3. Seasonal evolution of the shade acclimation coefficient for: (A) leaf net $\mathrm{CO}_{2}$ assimilation $\left(A_{\mathrm{n}}\right), \sigma_{\mathrm{A}}$, (B) leaf transpiration rate $(E), \sigma_{\mathrm{E}},(\mathbf{C})$ leaf stomatal conductance $\left(g_{\mathrm{S}}\right), \sigma_{\mathrm{g}}$, and $(\mathbf{D})$ the ratio $C_{i} / C_{a}, \sigma_{\mathrm{C}}$, in Layer 1 for the three screenhouses (W13, W34, and G36) as a function of days after transplant (DAT). Mean values followed by different letters are significantly different (separation by Fisher's least significant difference procedure at the $95 \%$ confidence level). and growth conditions of light; GonzalezReal and Baille, 2006). Because leaves of Layer 1 received less than that level around noon (Fig. 1), they were likely to have a higher efficiency to light than their counterparts in the OF, which were submitted to $P P F D$ conditions exceeding the amount of photosynthetic light saturation near noon.

Water use efficiency. Leaf aging and shading both acted in the same direction, lowering the values of intrinsic $\mathrm{WUE}_{\mathrm{i}}$. $\mathrm{WUE}_{\mathrm{i}}$ of sweet pepper leaves progressively decreased throughout the crop cycle (i.e., the rate of reduction in $g_{S}$ per unit of reduction in $A_{\mathrm{n}}$ is lower as leaves aged). This behavior was more marked for the screenhouse plants for which the values of $\mathrm{WUE}_{\mathrm{i}}$ were lower than those of the OF plants.

Instantaneous WUE has been observed either to increase (Centritto et al., 2000; Cohen et al., 2005; Lorenzo et al., 2003) or to decrease under shade as observed in sweet pepper plants (Díaz-Pérez, 2013; Jaimez and Rada, 2011), depending on plant species, environmental conditions, and the degree of shading (Díaz-Pérez, 2013). However, the influence of shading on intrinsic WUE (Stokes et al., 2000) of sweet pepper is scarce. The differences among instantaneous $\left(A_{\mathrm{n}} / E\right)$ and intrinsic $\left(A_{\mathrm{n}} / g_{\mathrm{S}}\right)$ WUE can be explained by the relative impact exerted by the components of total stomatal conductance $\left(g_{\mathrm{t}}\right)$ (leaf boundary layer conductance, $g_{\mathrm{b}}$, and $g_{\mathrm{S}}$ ) on the transpiration flux. When leaves are well coupled to the environment, $g_{\mathrm{S}}$ (a driver of intrinsic WUE) is the main determinant of $g_{\mathrm{t}}$ (a driver of the transpiration flux: $E=$ leaf-toair VPD. $g_{\mathrm{t}} \cong$ leaf-to-air VPD. $g_{\mathrm{S}}$ ) and values of instantaneous and $\mathrm{WUE}_{\mathrm{i}}$ can be expected to be similar. Under our experimental conditions, shading did not improve $\mathrm{WUE}_{\mathrm{i}}$ with respect to OF. This result might be explained through the impact of a reduction in light on $A_{\mathrm{n}}$ and $g_{\mathrm{S}}$. The values of net $\mathrm{CO}_{2}$ assimilation in the screenhouses were rather similar $(0<$ $\sigma_{\mathrm{A}}<+0.1$, DAT $\leq 107$ ) or lower than in the $\mathrm{OF}$ at the end of the crop cycle, whereas those of $g_{\mathrm{S}}$ exhibited sustained higher values under shade $\left(\sigma_{\mathrm{g}}<0\right)$. However, the positive effect of shading on $g_{\mathrm{S}}$, as a result of lower radiation load and leaf-to-air VPD, was not overcompensated for reductions in light on $A_{n}$, because it can be derived from the higher values of the ratio $C_{\mathrm{i}} / C_{\mathrm{a}}$ observed under a screenhouse. The increase in $C_{\mathrm{i}} / C_{\mathrm{a}}$ under shade from DAT 94 onward suggests that internal mesophyll limitations dominate the moderate reductions observed in $A_{n}$ at the end of the growth cycle over stomatal limitations.

\section{Conclusion}

Characterizing and understanding the effects of screenhouse cover materials on leaf photosynthetic attributes is relevant for the assessment of the productivity expected from such protective structures. Our study demonstrated that, within the relatively large range of shade provided by the screenhouses (from $\approx 13 \%$ to $36 \%$ ), the magnitude and temporal trend of net $\mathrm{CO}_{2}$ assimilation were only slightly 


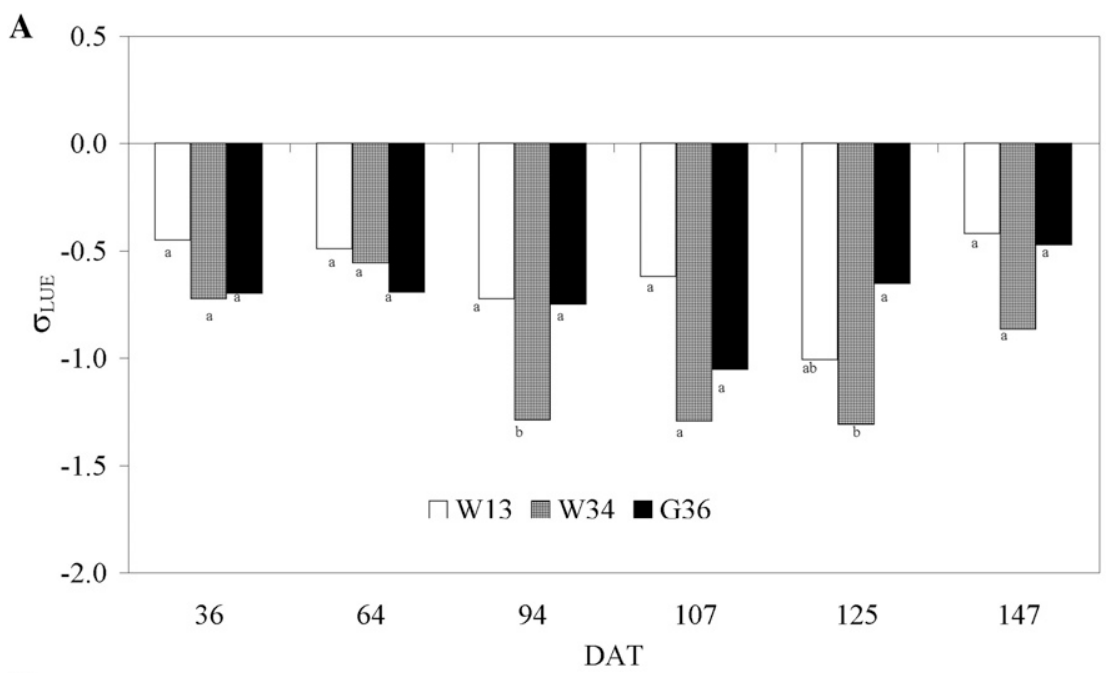

B

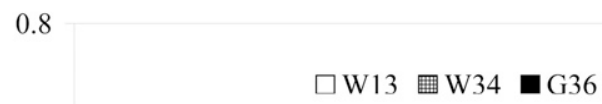

0.6

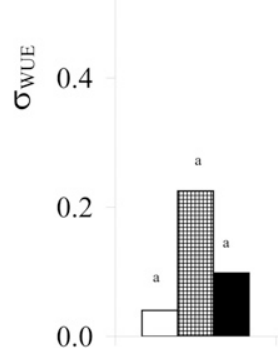

36

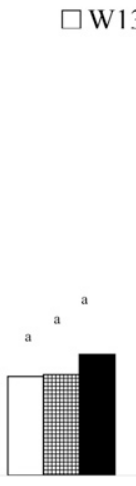

64

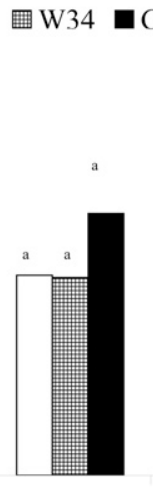

94

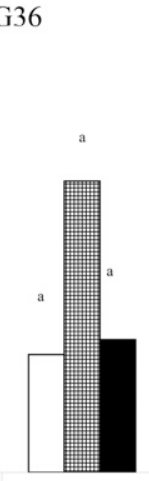

107

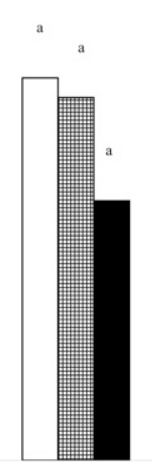

125

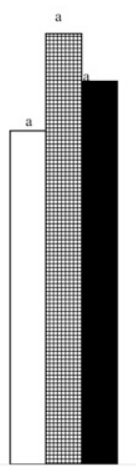

147

DAT

Fig. 4. Seasonal evolution of the shade acclimation coefficient for: (A) light-use efficiency, $\sigma_{\text {LUE }}$, and (B) intrinsic water use efficiency (WUE), $\sigma_{\mathrm{WUE}}$, in Layer 1 for the three screenhouses (W13, W34, and G36) as a function of days after transplant (DAT). Mean values followed by different letters are significantly different (separation by Fisher's least significant difference procedure at the $95 \%$ confidence level).

affected with respect to natural light conditions, therefore leading to a substantial increase in leaf LUE. More substantial changes, but still moderate, were observed for $E, g_{\mathrm{S}}$, and intercellular-to-ambient $\mathrm{CO}_{2}$ concentration ratio, resulting in a lower leaf $\mathrm{WUE}_{1}$ of screenhouse plants. In other words, the cost for screenhouse plants of maintaining similar $A_{\mathrm{n}}$ to OF plants was a decrease in WUE.

Additionally, the analysis of the shade acclimation coefficient $(\sigma)$ provided more insight into the short-term response of leaf photosynthetic attributes to a reduction in the amount of incident light. Some short-term changes observed in $\sigma$ before or during the flush in fruit set suggested that sweet pepper plants adjust the photosynthetic attributes to reach a balance between sources and sinks of assimilates. Parallel to short-term adjustments, ontogenic processes (e.g., leaf aging) were found to be predominant in driving the seasonal decrease in leaf photosynthetic performances independent of the light regime. In overall, sweet pepper plants grown under a screenhouse displayed light acclimation similar to that observed for the field-grown crop. This behavior was observed across a large interval of SI irrespective of the color and porosity of the screens.

\section{Literature Cited}

Acock, B., D.A. Charles-Edwards, D.J. Fitter, D.W. Hand, L.J. Ludwig, W.J. Wilson, and A.C. Withers. 1978. The contribution of leaves from different levels within a tomato crop to canopy net photosynthesis: And experimental examination of two canopy models. J. Expt. Bot. 29:815-827.

Adams, S.R., G.C. Woodward, and V.M. Valdés 2002. The effects of leaf removal and of modifying temperature set-points with solar radiation on tomato yields. J. Hort. Sci. Biotechnol. 77:733-738.

Aloni, B., L. Karni, Z. Zaidman, and A.A. Sschaffer. 1996. Changes of carbohydrates in pepper (capsicum annuuml.) flowers in relation to their abscission under different shading regimes. Ann. Bot. (Lond.) 78:163-168.

Aloni, B., T. Pashkar, and L. Karni. 1990. Partitioning of $[14 \mathrm{C}]$ sucrose and acid invertase activity in reproductive organs of pepper plants in relation to their abscission under heat stress. Ann. Bot. (Lond.) 67:371-377.

Baille, A., C. Kittas, and N. Katsoulas. 2001. Influence of whitening on greenhouse microclimate and crop energy partitioning. Agr. For. Meteorol. 107:293-306.

Barber, J. and B. Anderson. 1992. Too much of good thing: Light can be bad for photosynthesis. Trends Biochem. Sci. 17:61-66.

Castellano, S., G. Scarascia Mugnozza, G. Russo, D. Briassoulis, A. Mistriotis, S. Hemming, and D. Waaijenberg. 2008. Plastic nets in agriculture: A general review of types and applications. Appl. Eng. Agr. 24:799-808.

Centritto, M., F. Loreto, A. Massacci, F. Pietrini, M.C. Villani, and M. Zacchini. 2000. Improved growth and WUE in cherry saplings under reduced light intensity. Ecol. Res. 5:385-392.

Cockhull, K.E., C.J. Graves, and C.R.J. Cave. 1992. The influence of shading on yield of glasshouse tomatoes. J. Hort. Sci. 67:11-24.

Cohen, S., S. Moreshet, L. Le Guillou, J.-C. Simon, and M. Cohen. 1997. Response of citrus to modified radiation regime in semi-arid conditions. J. Expt. Bot. 48:35-44.

Cohen, S., E. Raveh, Y. Li, A. Grava, and E.E. Goldschmidt. 2005. Physiological responses of leaves, tree growth and fruit yield of grapefruit trees under reflective shade screens. Sci. Hort. 107:25-35.

Díaz-Pérez, J.C. 2013. Bell pepper (Capsicum annum L.) crop as affected by shade level: Microenvironment, plant growth, leaf gas exchange, and leaf mineral nutrient concentration. HortScience 48:175-182.

Dinar, M. and J. Rudich. 1985. Effect of heat stress on assimilate partitioning in tomato. Ann. Bot. (Lond.) 56:239-248.

Dueck, T.A., C. Grasshoff, G. Broekhuijsen, and L.F.M. Marcelis. 2006. Efficiency of light energy used by leaves situated in different levels of a sweet pepper canopy. Acta Hort. 711:201-206.

Egea, G., M.M. González-Real, A. Baille, P.A. Nortes, M.R. Conesa, and I. Ruiz-Salleres. 2012. Effects of water stress on irradiance acclimation of leaf traits in almond trees. Tree Physiol. 32:450-463.

Ehret, D.L., P.A. Jolliffe, and J.M. Molnar. 1989. Lighting for greenhouse vegetable production-An overview. Can. J. Plant Sci. 69:1309-1326.

Erickson, A.N. and A.H. Markhart. 2001. Flower production, fruit set, and physiology of bell pepper during elevated temperature and vapor pressure deficit. J. Amer. Soc. Hort. Sci. 126: 697-702.

Erickson, A.N. and A.H. Markhart. 2002. Flower developmental stage and organ sensitivity of bell pepper (Capsicum annum L.) to elevated temperature. Plant Cell Environ. 25: 123-130.

Field, C.B. and H.A. Mooney. 1986. The photosynthesis-nitrogen relationship in wild plants, p. 25-55. In: Givnish, T.J. (ed.). The economy of plant form and function. Cambridge University Press, Cambridge, UK.

Gent, M.P.N. 2007. Effect of degree and duration of shade on quality of greenhouse tomato. HortSci. 42:514-520.

Gonzalez-Real, M.M. and A. Baille. 2000. Changes in leaf photosynthetic parameters with leaf position and nitrogen content within a rose plant canopy (Rosa hybrida). Plant Cell Environ. 23:351-363.

Gonzalez-Real, M.M. and A. Baille. 2006. Plant response to greenhouse cooling. Acta Hort. 719:427-438. 
González-Real, M.M., A. Baille, and R.P. GutiérrezColomer. 2007. Leaf photosynthetic properties and radiation profiles in a rose canopy (Rosa hybrida L.) with bent shoots. Sci. Hort. 114:177-187.

González-Real, M.M., H.Q. Liu, and A. Baille. 2009. Influence of fruit sink strength on the distribution of leaf photosynthetic traits in fruitbearing shoots of pepper plants (Capsicum annuum L.). Environ. Expt. Bot. 66:195-202.

Gucci, R. and J.A. Flore. 1989. The effects of fruiting or fruit removal on leaf photosynthesis and dry mater distribution of tomato. Adv. Hortic. Sci. 3:120-125.

Hall, A.J. 1977. Assimilate source-sink relationships in Capsicum annuum L. I: The dynamics of growth in fruiting and deflorated plants. Aust. J. Plant Physiol. 4:623-636.

Healey, K.D., K.G. Rickert, G.L. Hammer, and M.P. Bange. 1998. Radiation use efficiency increases when the diffuse component of incident radiation is enhanced under shade. Aust. J. Agr. Res. 49:665-672.

Heuvelink, E., M.J. Bakker, A. Elings, R. Kaarsemaker, and L.F.M. Marcelis. 2005. Effect of leaf area on tomato yield. Acta Hort. 691:43-50.

Jaimez, R.E. and F. Rada. 2011. Gas exchange in sweet pepper (Capsicum chinense Jacq) under different light conditions. J. Agr. Sci. 3:134-142.

Jovicich, E., D.J. Cantliffe, and P.J. Stoffella. 2004. Fruit yield and quality of greenhouse-grown bell pepper as influenced by density, container, and trellis system. HortScience 14:507-513.

Katsoulas, N., C. Kittas, G. Dimokas, and Ch. Lykas. 2006. Effect of irrigation frequency on rose flower production and quality. Biosystems Eng. 93:237-244.

Kittas, C. and A. Baille. 1999. Influence of cover material and shading on the spectral distribu- tion of light under greenhouse. J. Agr. Eng. Res. 73:341-351.

Kittas, C., N. Katsoulas, N. Rigakis, T. Bartzanas, and E. Kitta. 2012. Effects on microclimate, crop production and quality of a tomato crop grown under shade nets. J. Hort. Sci. Biotechnol. 87:7-12.

Laisk, A., H. Eichelmann, V. Oja, B. Rasulov, E. Padu, I. Bichele, H. Pettai, and O. Kull. 2005. Adjustment of leaf photosynthesis to shade in a natural canopy: Rate parameters. Plant Cell Environ. 28:375-388.

Lawlor, D.W. 2002. Limitation to photosynthesis in water stressed leaves: Stomata vs. metabolism and the role of ATP. Ann. Bot. (Lond.) 89:871-885.

Li, A., N.C. Rajapakse, R.E. Young, and R. Oi. 2000. Growth responses of chrysanthemum and bell pepper transplants to photoselective plastic films. Sci. Hort. 84:215-225.

Lorenzo, P., M.C.S. Guerro, E. Medrano, M.L. Garcia, I. Caparros, and M. Giminez. 2003. External greenhouse mobile shading effect on microclimate water use efficiency and the yield of a tomato crop grown under different salinity levels of the nutrient solution. Acta Hort. 609:181-186.

Niinemets, Ü. 2007. Photosynthesis and resource distribution through plant canopies. Plant Cell Environ. 30:1052-1071.

Niinemets, Ü., O. Kull, and J.D. Tenhunen. 2004. Within-canopy variation in the rate of development of photosynthetic capacity is proportional to integrated quantum flux density in temperate deciduous trees. Plant Cell Environ. 27:293-313.

Papadopoulos, A.P. and S. Pararajasingham. 1997. The influence of plant spacing on light interception and use in greenhouse tomato (Licopersicum sculentum Mill.): A review. Sci. Hort. 69:1-29.
Raveh, E., S. Cohen, T. Raz, A. Grava, and E.E. Goldschmidt. 2003. Increased growth of young citrus trees under reduced radiation load in a semi-arid climate. J. Expt. Bot. 54:365-373.

Raviv, M. and Y. Antignus. 2004. UV radiation effect on pathogens and insect pests of greenhouse-grown crops. Photochem. Photobiol. 79:219-226.

Reuveni, R., M. Raviv, and R. Bar. 1989. Sporulation of Botrytis cinerea as affected by photoselective polyethylene sheets and filters. Ann. Appl. Biol. 115:417-424.

Rylski, I. and M. Spigelman. 1982. Effects of different diurnal temperature combinations on fruit set of sweet pepper. Sci. Hort. 17:101106.

Rylski, I. and M. Spigelman. 1986a. Effect of shading on plant development, yield and fruit quality of sweet pepper grown under conditions of high temperature and radiation. Sci. Hort. 29:31-35.

Rylski, I. and M. Spigelman. 1986b. Use of shading to control the time of harvest of red-ripe pepper fruits during the winter season in a highradiation desert climate. Sci. Hort. 29:37-45.

Stanhill, G. and S. Cohen. 2001. Global dimming: A review of the evidence for a widespread and significant reduction of global radiation with discussion of its probable causes and possible horticultural consequences. Agr. Meteorol. 107:255-278.

Stokes, V.J., M.D. Morecroft, and J.I.L. Morison. 2000. Comparison of leaf water use efficiency of oak and sycamore in the canopy over two growing seasons. Trees (Berl.) 4:297-306.

Tanny, J. and S. Cohen. 2003. The effect of a small shade net on the properties of wind and selected boundary-layer parameters above and inside a citrus orchard. Biosystems Eng. 84:57-67. 